\title{
O IMPOSTO TERRITORIAL RURAL (ITR) E A SUA INFLUÊNCIA SOBRE A ATIVIDADE FLORESTAL: UM ESTUDO DE CASO
}

\author{
Paulo de Tarso de Lara Pires ${ }^{1}$ \\ Roberto T. Hosokawa ${ }^{2}$ \\ Gilson Martins ${ }^{3}$ \\ J. R. Vieira ${ }^{4}$
}

\begin{abstract}
RESUMO
Este é um estudo de caso que trata das influências do Imposto Territorial Rural (ITR) sobre a atividade florestal. As áreas estudadas estão distribuídas ao longo da bacia hidrográfica do rio Iguaçu, na região Oeste do estado do Paraná. Os dados foram adquiridos nas fichas cadastrais do Censo de Estabelecimentos Agropecuários (1993) e o valor do ITR foi calculado de acordo com a metodologia estabelecida na Instrução Normativa-SRF $n^{0} .43$, de $07 / 05 / 97$. Com os dados foram feitas análises de regressão e análise multivariada. As variáveis coletadas por propriedade foram a área total (Atha), áreas com produtos vegetais (AGha), pastagens (Pha), benfeitorias (Bha), floresta nativa (Fha). Uma das principais conclusões do trabalho é que a variável Fha/Atha, que representa a área florestal da propriedade, tem um peso significativo para o decréscimo no valor do Imposto Territorial Rural.
\end{abstract}

Palavras-chave: tributação agrária, tributação florestal, legislação agrária, política florestal,

\section{FORESTS AND ITS INFLUENCE ON BRAZILIAN TAXATION ON RURAL PROPERTIES ITR: A CASE STUDY}

\begin{abstract}
This is a case study of the ITR (Brazilian Taxation on Rural properties) and its influence on forestry activities. The area studied is located along the Iguassu river, at the west region of the Paraná State. The data were collected from registers of "Censo de Estabelecimentos Agropecuários, 1993" (Agricultural properties census). The ITR was calculated according to the Instrução Normativa -SRF $n^{\circ} .43,07.05 .97$. Multivariate methods and regression analysis were applied for data analysis. The variables used were the total area (Atha), areas with agriculture and reforestation (Agha), pasture (Pha), constructions (Bha), native forests (Fha). One of the main conclusions is that the Fha/Atha variable, the forest area on the properties, have a significant weight for the reduction of the ITR values.
\end{abstract}

Key words: Agricultural Taxation, forest taxation, agricultural legislation, forests politics,

\section{INTRODUÇÃO}

O manejo sustentado, que alia a conservação do meio ambiente ao desenvolvimento econômico, é uma tendência mundial. Para que esta prática se viabilize, no entanto, é necessário o estabelecimento de uma política clara, voltada à atividade florestal, seja sob a óptica da produção, seja da conservação.

$\mathrm{O}$ confronto entre questões ambientais e econômicas tem representado um entrave para o desenvolvimento do setor florestal. De protestos ambientais de

\footnotetext{
${ }^{1}$ MSc., Doutorando em Economia e Política Florestal pela UFPR; Depto de Economia Rural e Extensão/UFPR; Rua dos Funcionários $n^{\circ} 1540$ - Curitiba Paraná - 80035-050 ptlpires@agrarias.ufpr.br)-fone(41) 350-5604

${ }^{2}$ Doutor em Ciências Florestais; Depto de Ciências Florestais /UFPR, Av. Lotário Meissner $\mathrm{n}^{0}$ 3400- Curitiba - PR - 80210-170

${ }^{3}$ Graduando em Engenharia Florestal pela Universidade Federal do Paraná - Rua Lotário Meissner n ${ }^{0} 3400$ - Curitiba-PR CEP 82210-170 (gilsonmartins@uol.com.br)

${ }^{4}$ Doutor em Direito pela PUC de São Paulo. UFPR, Praça Santos Andrade ${ }^{0} 50$ - Curitiba-PR
} 
pequenos grupos sociais organizados (ONGs), até pressões de grandes potências mundiais, o país procura equilibrar-se frente às suas próprias necessidades socioeconômicas. A busca de caminhos capazes de acomodar uma economia crescente a um meio ambiente saudável é incessante.

Esta pesquisa trata das influências das atividades florestais de produção e conservação da natureza sobre o Imposto Territorial Rural. Mais especificamente, tem os seguintes objetivos:

- realizar um estudo de caso num grupo de propriedades rurais, procurando estabelecer o grau de relacionamento entre o Imposto Territorial Rural, a área total da propriedade e seu grau de utilização em relação à agricultura, pastagem, floresta e benfeitorias;

- fornecer subsídios para a inclusão de dispositivos no Imposto Territorial Rural de incentivo ao desenvolvimento da atividade florestal, tanto de produção como de conservação da natureza

Os dados utilizados para $\mathrm{o}$ desenvolvimento do estudo foram coletados nas micro-regiões Sudoeste e Extremo Oeste, localizados na região Oeste do Estado do Paraná. Mais precisamente, as propriedades rurais estudadas, estão distribuídas ao longo da bacia hidrográfica do rio Iguaçu, nos municípios de Capitão Leônidas Marques, Boa Vista da Aparecida, Três Barras do Paraná, Quedas do Iguaçu, Cruzeiro do Iguaçu, Boa Esperança do Iguaçu e Nova Prata do Iguaçu

No Brasil, o ITR teve origem nos Estados-membros, com a Constituição de 1891. Atualmente está em vigor a Lei $\mathrm{n}^{0}$ 9.393/96 que estabeleceu novas regras para o ITR.

De acordo com TORRES (1993), "o ITR é um tributo com finalidade marcadamente extrafiscal, possuindo como objetivo principal promover a Reforma Agrária e a redistribuição de terras no País". É de incidência específica sobre a propriedade de bens imóveis, situados na denominada zona rural.

Segundo MACHADO (1993), o ITR é um imposto que, em parte, tem o caráter fiscal, para conseguir os recursos necessários à execução da Reforma Agrária e, em parte, tem o caráter extrafiscal, como instrumento para forçar o proprietário a promover a sua produção.

A função extrafiscal tem assumido uma importância crescente atualmente, com a problemática das desigualdades sociais. $\mathrm{O}$ tributo passa a exercer, preponderantemente, um objetivo econômico e social, indispensável à estrutura do próprio Estado, seja como instrumento regulador de produção, seja como reagente à repartição de riquezas ou na execução da reforma agrária e promoção da política agrária.

De acordo com CAMPOS (1982), o Governo, no exercício da política extrafiscal do ITR, poderá incentivar a construção de benfeitorias e obras de utilidade pública nas propriedades rurais oferecendo isenção fiscal pelas áreas ocupadas correspondentes. Além disso, poderá estimular a produção e o trabalho de colonização por meio de benefícios fiscais concedidos, desestimular a posse dos latifúndios e a combater os latifúndios improdutivos por meio de pesados tributos

De acordo com o artigo 15 da Lei 9.393/96, compete à Secretaria da Receita Federal, a administração do Imposto Territorial Rural, inclusive as atividades de arrecadação, tributo e fiscalização. A mesma lei determina ainda, em parágrafo único, que, no processo administrativo fiscal, compreendendo os procedimentos destinados à determinação e exigência do imposto, imposição de penalidades, repetição de indébito e solução de consultas, bem como a compensação do imposto, será observada a legislação prevista para os demais tributos federais.

A base de cálculo para o lançamento e cobrança do ITR é o valor fundiário, ou seja, o valor da terra nua (VTN), declarado pelo proprietário e não impugnado pela repartição fiscal ou por estar avaliado por avaliação cadastral. Para os efeitos da apuração do ITR é considerado o VTN, ou seja, o valor do imóvel, excluídos os valores relativos a: a) construções, instalações e benfeitorias; b) culturas permanentes e temporárias; c) pastagens cultivadas e melhoradas; d) florestas plantadas.

Partindo dessa base de cálculo, a legislação estabelece critérios de progressividade e regressividade de 
incidência para a determinação do tributo à ser recolhido pelo contribuinte, que são aplicados da seguinte forma:

Progressividade: a alíquota cresce a medida que o conjunto de informações analisado e extraído de ficha cadastral demonstra o uso inadequado do imóvel, o baixo rendimento econômico e a incompetência na exploração;

Regressividade: a alíquota decresce a medida que os referidos elementos indiquem o melhor uso no amplo sentido técnico, social e econômico que o proprietário dedica ao empreendimento na agricultura.

Nos termos do art. $153, \S 4^{0}$ da Constituição Federal/88 é assegurada a imunidade quanto à incidência sobre as pequenas glebas rurais, definidas em lei, quando as explore, só ou com sua família, o proprietário que não possua outro imóvel. Trata-se da imunidade relacionada com o mínimo existencial. O texto de 1988 excluiu a referência a extensão da gleba, que era no máximo de 25 ha (art. $21, \S 6^{0}$, CFB 1967/69) e que já fora de 20 ha (art. $\left.19, \S 1^{0}, \mathrm{CFB}, 1946\right)$, deixando-a para a definição da lei. A imunidade se estende não só ao proprietário mas também ao possuidor. Família, no dispositivo constitucional, significa todo grupo familiar, independente de haver casamento e prole legítima. A nova lei do ITR ( Lei 9.393/96) no seu artigo $2^{0}$, prevê que:

Art. $2^{0}$

"Parágrafo único - Pequenas glebas rurais são imóveis com área igual ou inferior a:

I - 100 ha, se localizado em município compreendido na Amazônia Ocidental ou no Pantanal matogrossense e sul-mato-grossense;

II - 50 ha, se localizado em município compreendido no Polígono das Secas ou na Amazônia Oriental;

III - 30 ha se localizada em qualquer outro município."

Estão isentas do ITR as áreas de preservação permanente e de reserva legal, previstas na Lei $4.771 / 65$, com redação dada pela Lei 7.803/89. Estão isentas também as áreas de interesse ecológico para a proteção de ecossistemas, assim declaradas mediante ato do órgão competente, federal ou estadual, e que ampliem as restrições de uso previstas na alínea anterior. Finalmente, estão isentas as áreas comprovadamente imprestáveis para qualquer exploração agrícola, pecuária, granjeira, aqüícola ou florestal, declaradas de interesse ecológico mediante ato do órgão competente, federal ou estadual.

Os imóveis pertencentes a União, Estados, Distrito Federal e Municípios, ou a suas autarquias e fundações e a instituições de educação e assistência social, sem fins lucrativos, bem como imóveis pertencentes à associação ou cooperativa de produção, compreendidos em programas de reforma agrária estão dispensados da declaração do ITR.

Para os imóveis que apresentem baixo grau de utilização da terra, a alíquota será multiplicada por coeficientes de progressividade. Se o imóvel for mantido inexplorado ou mal explorado, a alíquota do ITR será progressiva, aumentando também no tempo. Para obter o valor do ITR multiplica-se o valor da terra nua tributável pela alíquota estabelecido na Instrução Normativa - SRF no 43/97.

OLIVEIRA (1995) afirma que, dentre os critérios adotados pela doutrina para classificação das espécies tributárias, o critério de finalidade merece destaque. Por este critério distingue-se os tributos em fiscais (finalidade de arrecadação de recursos financeiros), parafiscais (se destinam ao custeio de atividades paralelas à da administração pública direta) e extrafiscais (que atendem a fins outros que não a arrecadação, mas, geralmente, à correção de situações sociais indesejadas e à condução de estímulos). Nessa última modalidade está inserido, em grande parte o Imposto Territorial Rural.

\section{MATERIAIS E MÉTODOS}

Os dados utilizados para a realização dos estudos foram coletados nas fichas cadastrais do Censo de Estabelecimentos Agropecuários do Instituto Brasileiro de Geografia e Estatística (1993).

Para a caracterização da área de estudo, foram estudadas todas as 813 propriedades contidas no censo. Num segundo momento, para o estudo do ITR propriamente dito, foram utilizadas 256 propriedades que, de acordo com a legislação vigente (Lei $n^{0}$. 9.393/96), estariam obrigadas a recolher o ITR. As 
propriedades isentas foram excluídas da análise final.

As variáveis coletadas por propriedade foram, em hectares, 1) a área total (Atha), 2) áreas com produtos vegetais (AGha), 3) pastagens (Pha), 4) benfeitorias (Bha), 5) floresta nativa (Fha). O valor do Imposto Territorial Rural para cada propriedade foi calculado de acordo com a metodologia estabelecida na Instrução Normativa-SRF $n^{0} .43$, de 07/05/97.

De acordo com a referida instrução normativa, consideram-se áreas com produtos vegetais aquelas cultivadas com culturas temporárias (milho, soja, feijão e outras) e as com culturas permanentes, inclusive as reflorestadas com essências exóticas ou nativas com destinação comercial. As áreas de pastagem referem-se àquelas áreas de pasto natural e de pasto plantado. Áreas de benfeitorias são aquelas efetivamente ocupadas com casas, galpões, estábulos, currais, mangueiras, aviários, pocilgas e outras instalações para abrigo ou tratamento de animal, terreiro ou similares para secagem e beneficiamento de produtos agrícolas, barragens, represas, tanques, estradas, eletricidade rural, cercas e outras benfeitorias não relacionadas à atividade rural. No item "mata nativa", foram consideradas as áreas com cobertura florestal nativa sem finalidade comercial.

Foram efetuadas análises da estrutura fundiária da área de estudo, de acordo com os critérios adotados no Censo Agropecuário do IBGE, Paraná - 1985. A estrutura atual do local foi definida de acordo com o número de propriedades por classe de área, quantidade de área com produtos vegetais, pastagem, floresta $\mathrm{e}$ benfeitoria em cada uma das classes.

Foram consideradas pequenas propriedades, de acordo com Instrução Normativa - SRF $\mathrm{n}^{0} .43$ de 07/05/97, os estabelecimentos com área inferior à 30 ha, como médias àquelas entre 30 e 100 ha $\mathrm{e}$ grandes aquelas com área superior à 100ha. Foi calculada a quantidade em valor absoluto de cada uma das variáveis por classe de área, e as estatísticas descritivas para cada grupo de propriedades.

Num primeiro momento do trabalho, foi realizada uma análise descritiva de cada uma das variáveis, em 256 observações selecionadas.

Para que parte dos objetivos do trabalho pudesse ser alcançada, foi realizado um estudo da estrutura dos dados, para detectar fatores que explicassem, de forma mais eficiente, o valor alcançado pelo Imposto Territorial Rural.

As análises estatísticas foram realizadas por meio dos programas SAEG e STATGRAPHICS 6.0. Com relação às variáveis e seus coeficientes, ficou estabelecido que:

a) AT, VTNT $>0$; b) AG/AT < 0;

c) $\mathrm{P} / \mathrm{AT}<0$; d) F/AT $<0$,

e) B/AT < 0; f) AG, P, F, B <0,

Foi admitida a variável ITR como variável dependente e passou-se à análise propriamente dita.

A hipótese central do estudo foi a de que as variações no valor do Imposto Territorial Rural podem ser determinadas pelas variações na área total da propriedade e pelas variações nas proporções de área com produtos vegetais, pastagem, florestas naturais e benfeitorias. O modelo analítico inicial é:

ITR $=\beta_{0}+\beta_{1}$ ATha $+\beta_{2}$ AGha $+\beta_{3}$ Pha + $\beta_{4}$ Fha $+\beta_{5}$ Bha $+\beta_{6}$ Fha/ATha $+\beta_{7}$ AGha/ATha $+\beta_{8}$ Pha/ATha $+\beta_{9}$ Bha/ATha $+\beta_{10} \mathrm{VTNT}+\varepsilon$

\section{RESULTADOS}

Como pode ser observado na Tabela 1, dentre os estabelecimentos rurais pesquisados observou-se a predominância de pequenas propriedades, com um total de 490 estabelecimentos, representando $60,26 \%$ do número total das propriedades. $\mathrm{Na}$ faixa das médias propriedades (de 30ha até 100ha) foram enquadradas 263 propriedades, representando $32,34 \%$ do total. Finalmente, 60 grandes propriedades, com área superior a $100 \mathrm{ha}$, representam $7,38 \%$ 
Tabela 1 - Área, Tamanho Médio E Uso Do Solo Dos Estabelecimentos Rurais Na Área De Estudo

\begin{tabular}{|c|c|c|c|c|c|c|c|c|c|c|c|c|c|}
\hline \multirow{2}{*}{$\begin{array}{l}\text { Grupos } \\
\text { de área }\end{array}$} & \multicolumn{2}{|c|}{ Propriedade } & \multicolumn{2}{|c|}{ Área total } & \multirow{2}{*}{$\begin{array}{c}\begin{array}{c}\text { Área } \\
\text { méd. }\end{array} \\
\text { ha }\end{array}$} & \multicolumn{2}{|c|}{ Agricultura } & \multicolumn{2}{|c|}{ Pastagem } & \multicolumn{2}{|c|}{ Floresta } & \multicolumn{2}{|c|}{ Benfeitoria } \\
\hline & $\mathrm{N}^{0}$ & $\%$ & ha & $\% \mathrm{~T}$ & & ha & $\%$ & ha & $\%$ & ha & $\%$ & ha & $\%$ \\
\hline$<10$ ha & 291 & 35,79 & 1575.3 & 1,37 & 5,41 & 630,2 & 39,4 & 547,1 & 36,4 & 81,7 & 5,2 & 90,4 & 5,7 \\
\hline $\begin{array}{c}10 \text { a } 30 \\
\text { ha }\end{array}$ & 199 & $24 ., 47$ & 2802.9 & 2,45 & 14,08 & 935,4 & 33,4 & 944,9 & 33,7 & 82,8 & 2,95 & 102,3 & 3,6 \\
\hline $\begin{array}{c}30 \text { a } 50 \\
\text { ha }\end{array}$ & 196 & 24,10 & 6153.1 & 5,38 & 31,3 & 1661,1 & 27,0 & 2835,7 & 46,1 & 317,1 & 5,15 & 123,7 & 2,0 \\
\hline $\begin{array}{c}50 \text { a } 100 \\
\text { ha }\end{array}$ & 67 & 8,24 & 4807.3 & 4,20 & 71,75 & 994,0 & 20,6 & 2409,4 & 50,1 & 310,8 & 6,46 & 109,1 & 2,26 \\
\hline$>100 \mathrm{ha}$ & 60 & 7,38 & 98947.4 & 86,57 & 1649,12 & 44962,4 & 22,2 & 8557,1 & 8,6 & 26405,4 & 26,6 & 1323,7 & 1,33 \\
\hline Total & 813 & 100 & 114286.1 & 100 & 140,57 & 47183,1 & 22,9 & 15294,2 & 13,38 & 27197,8 & 23,8 & 1749,2 & 1,53 \\
\hline
\end{tabular}

Fonte: Dados brutos do Censo Agropecuário (1993)

As pequenas propriedades somaram 4378,20 ha, ou seja $3,82 \%$ da área total. As propriedades de tamanho médio importaram em $9,58 \%$ da área total, com 10.960,40ha. As 60 grandes propriedades possuem juntas uma área total de $98.947,40$ ha, representando $86,57 \%$ da área total.

As pequenas propriedades possuíam $35,75 \%$ de suas áreas com produção vegetal, $34,7 \%$ com pastagem, $4,40 \%$ com benfeitorias e apenas 3,75\% ocupadas com florestas naturais.

Dentre as médias propriedades, houve um predomínio de áreas ocupadas com pastagem $(47,85 \%)$, seguidas pelas áreas utilizadas para o plantio de produtos vegetais com finalidade comercial $(24,22$ $\%$ ), áreas com floresta com 5,72\% e benfeitorias com $2,12 \%$ do total.
Com relação às grandes propriedades, que concentram a maior quantidade de terra, foram distribuídas da seguinte forma: $22,2 \%$ ocupada com agricultura, 8,6\% com áreas de pastagem, $1,33 \%$ com benfeitorias e $26,6 \%$ da área total era coberta por florestas nativas.

Como pode ser observado na tabela 2, uma grande porção da área total (86.57\%) está centrada em 60 propriedades que significam $7.38 \%$ do número total de propriedades, enquanto os pequenos proprietários não ultrapassam os $3.82 \%$ da área total. A análise evidencia ainda, uma maior concentração de áreas ocupadas com florestas nativas em grandes propriedades e uma baixa concentração nos pequenos estabelecimentos rurais.

Tabela 2 - Fatores Selecionados Na Análise Fatorial

\begin{tabular}{lll}
\hline Fator 1 & Fator 2 & Fator 3 \\
\hline ATha $(, 99443)$ & AGha/Atha $(, 91695)$ & Fha / Atha $(, 97698)$ \\
AGha (,99263) & Pha/Atha $(-, 89171)$ & \\
Fha (,99214) & & \\
Bha $(, 99635)$ & & \\
\hline
\end{tabular}

Partindo-se do modelo analítico previamente estabelecido, estimou-se, por meio do método de mínimos quadrados ordinários, a equação do ITR em função das variáveis independentes definidas no modelo. $\begin{array}{ccc}\text { Entre } & \text { as } & \text { variáveis estudadas, } \\ \text { verificou-se } & \text { a } & \text { existência de }\end{array}$ multicolinearidade entre as variáveis independentes ATha, VTNT, AGha, Fha e Bha, a julgar pela proximidade entre as correlações simples das variáveis independentes, com a raiz quadrada do coeficiente de determinação (Matriz de correlação - Tabela 3). 
Tabela 3 Matriz De Correlações

\begin{tabular}{|l|l|l|l|l|l|l|l|l|l|l|l|}
\hline & ITR & ATHA & AGH & PHA & FHA & BHA & $\begin{array}{l}\text { FHATH } \\
\text { A }\end{array}$ & $\begin{array}{l}\text { AGHAT } \\
\text { HA }\end{array}$ & $\begin{array}{l}\text { PHATH } \\
\text { A }\end{array}$ & $\begin{array}{l}\text { BHATH } \\
\text { A }\end{array}$ & VTNT \\
\hline ITR & 1.0000 & .99565 & .99506 & .57752 & .99384 & .99309 & .10874 & .06202 & -.12963 & -.01216 & .99693 \\
\hline ATHA & .99565 & 1.0000 & .99979 & .55495 & .99969 & .99854 & .11241 & .06484 & -.11840 & -.00697 & .99967 \\
\hline AGH & .99506 & .99979 & 1.0000 & .54032 & .99972 & .99848 & .11239 & .07544 & -.12595 & -.00612 & .99919 \\
\hline PHA & .57752 & .55495 & .54032 & 1.0000 & .53815 & .54461 & -.04629 & -.21375 & .22919 & -.05635 & .57236 \\
\hline FHA & .99384 & .99969 & .99972 & .53815 & 1.0000 & .99859 & .11932 & .06483 & -.12067 & -.00539 & .99873 \\
\hline BHA & .99309 & .99854 & .99848 & .54461 & .99859 & 1.0000 & .11420 & .06470 & -.11949 & .03485 & .99784 \\
\hline FHATHA & .10874 & .11241 & .11239 & -.04629 & .11932 & .11420 & 1.0000 & -.08096 & -.35731 & .00945 & .10760 \\
\hline AGHATHA & .06202 & .06484 & .07544 & -.21375 & .06483 & .06470 & -.08096 & 1.0000 & -.70382 & .03700 & .06454 \\
\hline PHATHA & -.12963 & -.11840 & -.12595 & .22919 & -.12067 & -.11949 & -.35731 & -.70382 & 1.0000 & -.08206 & -.11687 \\
\hline BHATHA & -.01216 & -.00697 & -.00612 & -.05635 & -.00539 & .03485 & .00945 & .03700 & -.08206 & 1.0000 & -.00861 \\
\hline VTNT & .99693 & .99967 & .99919 & .57236 & .99873 & .99784 & .10760 & .06454 & -.11687 & -.00861 & 1.0000 \\
\hline
\end{tabular}

A presença de multicolinearidade leva a estimadores imprecisos, em virtude das suas grandes variâncias, fazendo com que os testes de hipótese sobre os parâmetros não sejam confiáveis ( KELEJIAN e OATES, 1978) citados por IGNÁCIO (1991).

Visando agrupar no mesmo fator as variáveis altamente correlacionadas e posteriormente a eleição de uma variável que represente as demais, utilizou-se a técnica de análise fatorial em componentes principais.

As variáveis que compõem os 3 fatores, podem ser observados na tabela 2 .

Assim sendo, no $1^{0}$ Fator foi selecionada a variável Atha, por estar altamente correlacionada com as demais variáveis deste fator, variando no mesmo sentido.

No $2^{0}$ Fator foram selecionadas as variáveis Agha/Atha e Pha/Atha por apresentarem altos carregamentos neste fator e sinais contrários. A razão destas variáveis apresentarem sinais contrários, se deve ao fato destas atividades serem concorrentes nas áreas das propriedades. Isto é, numa região onde a estrutura fundiária está estabelecida, para que se aumente a proporção de área com pastagem numa propriedade rural, provavelmente haverá uma redução na área de plantio agrícola. Estas variáveis apresentam uma correlação linear de - 0,70382, não mostrando multicolinearidade para o modelo.

No $3^{0}$ Fator foi selecionada a variável Fha/ATha, com carregamento neste fator de 0,97698 .

Como a variável Bha/ATha não se mostrou significante, com comunalidade de 0.0237 , esta não foi considerada no modelo final de regressão.
Com relação a significância, após o ajuste, todos os parâmetros estimados por meio do método dos mínimos quadrados ordinários mostrou-se significativo a 0,01 de probabilidade.

A equação final do Imposto Territorial Rural, é a seguinte:

ITR $=7113,13+9.3670 *$ ATha 7595,97* AGha/ATha - 8538,97* Pha/ATha - 8208,53 Fha/ATha

Com relação ao poder explicativo do modelo, indicado pelo coeficiente de determinação $\mathrm{R}^{2}$ ( .99201), $\bar{R}^{2}(.99108) \mathrm{e}$ F ( 7796.33), os três indicam alto poder explicativo.

O modelo estatístico final obtido para o ITR permite concluir que, com base na amostra analisada, a variável Fha/ATha, teve um peso preponderante no cálculo do valor do imposto a ser recolhido. Demonstra ainda, que um aumento na área com floresta nativa, implica na redução do valor do imposto a ser pago pelo proprietário rural, haja visto que o sinal da derivada do ITR em relação a variável Fha/ATha é negativo.

\section{CONCLUSÕES}

O modelo proposto, referente ao valor do ITR, possui um bom poder de explicação. As variações nas variáveis explicativas do modelo conseguem responder por mais de $90 \%$ das variações no ITR.

A variável Fha/Atha, que representa a área florestal da propriedade, tem um peso significativo para o decréscimo no valor do Imposto Territorial Rural à ser recolhido pelo proprietário rural.

Tanto as pequenas e médias propriedades possuíam área média de floresta menores do que $20 \%$ da área total 
da propriedade estabelecidos no código florestal, não cumprindo desta forma, integralmente com a função social da propriedade.

As pequenas propriedades, mesmo quando em desacordo com a legislação ambiental vigente, que prevê uma área mínima de $20 \%$ de cada propriedade ocupados por florestas, são em grande parte , imunes do ITR.

\section{RECOMENDAÇÕES}

Em função do peso representado pela variável Fha/ATha no cálculo do ITR, é urgente a criação de dispositivos que incentivem, principalmente, $\mathrm{o}$ pequeno $\mathrm{e}$ médio produtores rurais a recuperar as áreas com floresta, já que estas não chegam a representar nem $10 \%$ da área das propriedades nos estabelecimentos rurais estudados.

$\mathrm{Na}$ solução dos problemas de área de florestas em pequenas propriedades, é fundamental um dispositivo de lei que obrigue $\mathrm{o}$ produtor rural a cumprir a legislação ambiental vigente, como limitante ao benefício da isenção fiscal.

Estudos mais aprofundados são imprescindíveis para o estabelecimento de novas políticas de desenvolvimento econômico. Cientes da eminência de reformas no sistema tributário é essencial a preparação do setor florestal para a proposição de políticas que favoreçam seu desenvolvimento.

\section{BIBLIOGRAFIA CITADA}

AFFONSO, R.B.A.;SILVA P.L.B. (Org.). Reforma tributária e a Federação. São Paulo: FUNDAP: Editora da Universidade Estadual Paulista, 1995.

CAMPOS, D. Imposto sobre a Propriedade Territorial Rural. In: MARTINS, I.G.
Curso de Direito Tributário. São Paulo: Saraiva : Centro de Estudos de Extensão Universitária, 1982. p. 451 - 461.

ESTUDO DE IMPACTO AMBIENTAL, 1993. Usina Hidrelétrica de Salto Caxias, Rio Iguaçu, Paraná. Companhia Paranaense de Energia, Intertechne, Engevix, Esteio. V.III, cap.3.

IGNÁCIO, S. Análise das relações estruturais de oferta de milho no Estado do Paraná, 1996/1998. Viçosa, 1991.111 p. Dissertação (Mestrado), Universidade Federal de Viçosa.

IPARDES. Agrupamento dos municípios paranaenses segundo variáveis sócioeconômicas: uma análise estatística. Curitiba, $1995.57 \mathrm{p}$

KLEIN, R.M. Os aspectos ecológicos do pinheiro - bravo - Sellowia, v.12, n.12, p.17-48, 1960.

KMENTA, J. Elementos de econometria. São Paulo: Atlas, 1978. 670 p.

MACHADO H. B. Curso de Direito Tributário. Rio de Janeiro: Ed. Forense, 1993. p. 246-251

OLIVEIRA, J.M.D. Direito tributário e meio ambiente: proporcionalidade, tipicidade aberta, afetação da receita. Rio de Janeiro: Renovar, 1995. 120 p.

PIRES, P.T.L.O ITR e sua influência sobre a atividade florestal. Curitiba, 1999.125f. Dissertação (Mestrado em Ciências Florestais) - Setor de Ciências Agrárias, Universidade Federal do Paraná.

SBS. Programa de Preservação e Reconstituição da Cobertura Florestal do Brasil. Revista Silvicultura, São Paulo, v. 13, n. 50, p. 55-60, 1993.

TORRES R. L. Curso de Direito Financeiro e Tributário: de acordo com a Emenda Constitucional $\mathrm{n}^{0}$ 3, de 1993. Rio de Janeiro: Renovar, 1993. p. 314. 